\title{
Anatomia comparativa da artéria facial de Sus scrofa scrofa Linnaeus, 1758 (Mammalia, Suidae)
}

\author{
Lucas de Assis Ribeiro ${ }^{{ }^{*}}$ \\ Tiago Machado Vieira ${ }^{1}$ \\ Frederico Ozanam Carneiro e Silva ${ }^{1}$ \\ Henrique Inhauser Riceti Magalhães ${ }^{2}$ \\ Ygor Henrique de Paula ${ }^{2}$ \\ Fabiano Braz Romão ${ }^{2}$ \\ Jeferson Borges Barcelos ${ }^{3}$ \\ Roseâmely Angélica de Carvalho-Barros ${ }^{4}$ \\ ${ }^{1}$ Universidade Federal de Uberlândia, Campus Umuarama \\ Rua Ceará s/n, Bloco 2D, Umuarama, CEP 38400-902, Uberlândia - MG, Brasil \\ ${ }^{2}$ Centro Universitário de Patos de Minas, Patos de Minas - MG, Brasil \\ ${ }^{3}$ Fundação Presidente Antônio Carlos, Uberlândia - MG, Brasil \\ ${ }^{4}$ Universidade Federal de Goiás, Campus Catalão, Catalão - GO, Brasil \\ * Autor para correspondência \\ lucasassis83@yahoo.com.br
}

Submetido em 13/06/2017

Aceito para publicação em 11/10/2017

\section{Resumo}

O javali encontra-se amplamente distribuído pelo homem em diversas partes do mundo, com exceção da Antártica. É sabido que a artéria facial e seus ramos são responsáveis por manter o suprimento sanguíneo das estruturas relacionadas com a mastigação, deglutição e produção de saliva. Diante do exposto, objetivou-se descrever as origens e distribuições das artérias faciais direita e esquerda do javali. As artérias faciais deste suídeo originaram-se da artéria carótida externa em todos os espécimes e distribuíram-se em ramos faríngeo, glandulares, musculares e ramos para linfonodos mandibulares. Ramos anastomóticos da artéria facial com a bucal e com o ramo milo-hioideo da artéria alveolar inferior foram identificados. Essa característica demonstra que a região de alocação da artéria facial nesses animais necessita de um expressivo contingente para irrigação, colaborando muito com sua eficácia funcional, bem como com o modus viventis deste animal.

Palavras-chave: Irrigação; Javali; Morfologia

\section{Abstract}

Comparative anatomy of the facial artery of Sus scrofa scrofa Linnaeus, 1758 (Mammalia, Suidae). The wild boar is broadly distributed in several parts of the world by man, with the exception of Antarctica. It is known that the facial artery and its branches are responsible for maintaining the blood supply of structures 
related to chewing, swallowing, and the production of saliva. The aim of this study is to describe the origin and distribution of the right and left facial arteries of the boar in the context of foraging. The facial arteries of this boar species originated from the external carotid artery in all specimens and were distributed in the pharyngeal, glandular, and muscular branches as well as the branches to the mandibular lymph nodes. The anastomotic branches of the facial artery with the buccal and mylohyoid branch of the inferior alveolar artery were also identified. This feature shows that the region of allocation of the facial artery in these animals requires a large network for irrigation, which contributes to the functional efficacy as well as the modus viventis of this animal.

Key words: Boar; Irrigation; Morphology

\section{Introdução}

O javali é um ungulígrado pertencente à família Suidae e gênero Sus (LONG, 2003), sendo uma espécie antiga e originária da Eurásia e de partes da África e Ásia, a qual foi amplamente introduzida de forma intencional em todas as partes do mundo pelo homem (COURCHAMP et al., 2003; LONG, 2003), com exceção da Antártica (LONG, 2003).

Acreditava-se que a entrada desses animais em território brasileiro se deu pela divisa do Rio Grande do Sul com o Uruguai, principalmente após a queda na disponibilidade de alimentos, devido à seca em 1989 (VALÉRIO, 1999; FRANKENBERG, 2005). No entanto, essa invasão também ocorreu de forma clandestina, quando pessoas adentravam no país com estes para fins reprodutivos (TIEPOLO; TOMAS, 2006; DEBERDT; SCHERER, 2007).

No Brasil, seu crescimento populacional está relacionado com a falta de predadores e principalmente pela alta oferta de alimentos (DEBERDT; SCHERER, 2007), podendo ser de origem animal ou vegetal, dependendo de sua disponibilidade, caracterizando assim um comportamento alimentar oportunista (GENOV, 1981; BAUBET et al., 2004). A partir do hábito de forrageamento, buscam e apreendem raízes, bulbos, invertebrados e tubérculos.

Esses suídeos também se alimentam de fungos, frutas, ovos de variadas espécies (GENOV, 1981; CHOQUENOT et al., 1996), pequenos animais (TIEPOLO; TOMAS, 2006), e produções agrícolas (DEBERDT; SCHERER, 2007). A mastigação deste animal é favorecida por uma longa e afiada presa na região mandibular e uma rígida arcada dentária, que permitem o consumo de alimentos macios e maciços, além de ajudar em atitudes de preservação e combate (OLIVER; BRISBIN, 1993; LONG, 2003).

No tocante à irrigação sanguínea e às estruturas anatômicas a elas direcionadas, podem ser evidenciadas diferenças que necessitam ser averiguadas para se determinar a relação contínua presente neste processo morfofuncional (MAIA et al., 2014). É sabido que a artéria facial e seus ramos são responsáveis por manter o suprimento sanguíneo das estruturas relacionadas com a mastigação, deglutição e produção de saliva (GETTY, 1986). Considerando que o conhecimento anatômico auxilia com eficácia as intervenções de diversas naturezas como farmacológicas e cirúrgicas, torna-se evidente a importância de se estudar, detalhadamente, $o$ perfil das artérias faciais (MACÊDO, 2012), em diversas espécies. Com base no exposto, objetivou-se descrever as origens e distribuições das artérias faciais direita e esquerda de javali.

\section{Material e Métodos}

Foram analisadas seis cabeças de javalis juvenis, totalizando 12 hemicabeças (três machos e três fêmeas). O material utilizado foi proveniente do acervo do Laboratório de Anatomia Animal da Faculdade de Medicina Veterinária e Zootecnia (FAMEV-UFU).

O sistema arterial foi marcado através da aorta torácica, por meio de incisão no nono espaço intercostal esquerdo. O referido vaso foi canulado e preenchido com solução aquosa de látex $\left(\right.$ Artecola $^{\circledR}$ - Altamira Indústria e Comércio de Látex), a 50\%, corado com pigmento específico na cor vermelha (Suvinil ${ }^{\circledR}$ Tintas e Pigmentos - corante para tinta látex). A fixação ocorreu mediante injeções intramusculares, subcutâneas e intracavitárias 
de solução aquosa de formaldeído a $10 \%\left(\right.$ Chemco $^{\circledR}-$ formaldeído solução GEIII).

Para a dissecação das hemicabeças, o rebatimento da pele e músculo cutâneo da face foi realizado no terço cranial do pescoço no sentido caudocranial. Ao nível da região temporal, a artéria carótida externa foi identificada $\mathrm{e}$, subsequentemente ao seu isolamento, identificaram-se as artérias faciais direita e esquerda. Ambas as artérias foram dissecadas no sentido ventromediorostral, a partir de suas origens nas artérias carótidas externas, e todos os ramos emitidos foram descritos e contabilizados.

A documentação fotográfica foi realizada mediante uma câmera Sony DSC-W510 (Cyber-shot 12.1 mega pixels). A nomenclatura anatômica utilizada para a designação das estruturas anatômicas tratadas neste trabalho esteve de acordo com a International Committee on Veterinary Gross Anatomical Nomenclature (2012). O estudo foi aprovado pelo Comitê de Ética na Utilização de Animais da Universidade Federal de Uberlândia, protocolo no 103/13.

\section{Resultados}

A artéria facial originou-se da margem lateroventral da artéria carótida externa, dorsalmente ao tendão de origem do músculo digástrico, e se estendeu ventralmente, acompanhando medialmente o ramo e ângulo da mandíbula e, subsequentemente, em sentido rostral, o corpo da mandíbula (Figura 1).

FIGURA 1: Origem e distribuição da artéria facial de javali. Face lateral de hemicabeça esquerda de javali; dissecção da região temporal e do terço caudal da região intermandibular. Artéria facial (f) e artéria carótida externa (ce). Distribuição da artéria facial (f) ao longo de seu trajeto: ramo faríngeo da artéria facial (fr), ramo para a glândula salivar mandibular (c'), ramos para a glândula salivar parótida (c), ramo para o linfonodo mandibular (l) e ramos para o músculo cutâneo da face (e). Demais estruturas visualizadas: tendão de origem do músculo digástrico $(\mathrm{t})$, músculo digástrico $(\mathrm{md})$, músculo pterigoideo medial (pm), glândula salivar parótida (gp), glândula salivar mandibular (gm), artéria alveolar inferior (i), ramo milo-hioideo da artéria alveolar inferior (r) e anastomose convergente do ramo milo-hioideo da artéria alveolar inferior com a artéria facial (a), formando a artéria digástrica (d). Barra de escala $=1 \mathrm{~cm}$.

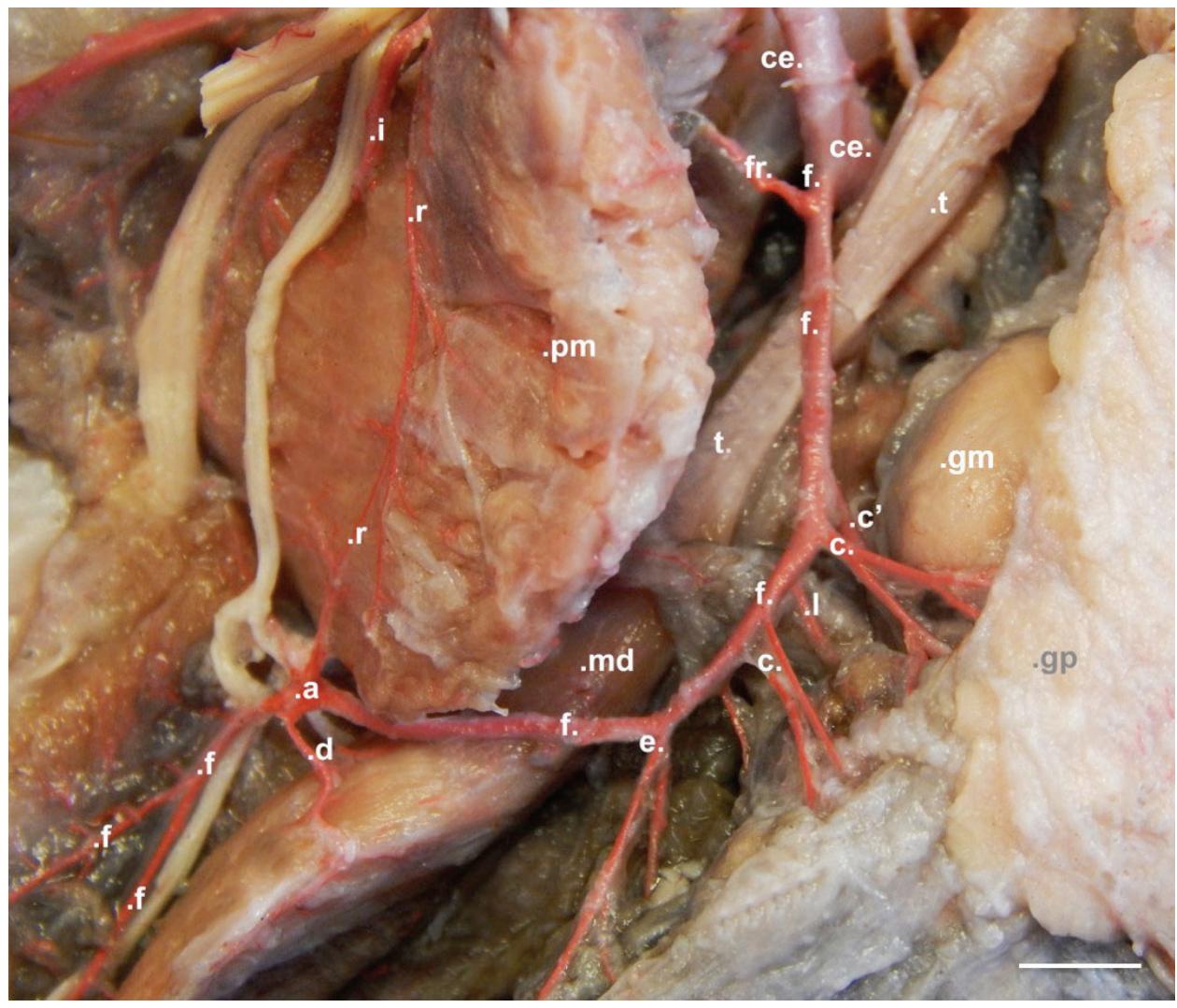


No tocante à distribuição, a artéria facial emitiu os seguintes ramos: ramo faríngeo, que se destacou da margem mediorostral e se distribuiu para os músculos pterigoideo medial e estiloglosso, além da parede dorsolateral da faringe e o palato mole; ramos musculares, que se destacaram rostralmente e dorsomedialmente tais como: os ramos caudal, médio e rostral para os músculos pterigoideo medial e masseter; ramos glandulares, que foram emitidos para as glândulas salivares mandibular e parótida; ramos para os linfonodos mandibulares; ramos para o músculo cutâneo da face; ramos para o músculo digástrico; ramos para o músculo bucinador parte molar e ramos para o músculo milo-hioide (Figuras 1 e 2).

Duas anastomoses foram evidentes bilateralmente em todas as hemicabeças, a saber: anastomose da artéria facial com a artéria bucal (Figura 3); anastomose convergente do ramo milo-hioideo da artéria alveolar inferior com a artéria facial, formando a artéria digástrica (Figura 4).

FIGURA 2: Distribuição da artéria facial de javali. Face lateral de hemicabeça direita de javali; dissecção do terço caudal da região intermandibular. Artéria facial (f), ramo caudal para os músculos pterigoideo medial e masseter (k), ramo médio para os músculos pterigoideo medial e masseter (k'), ramo rostral para os músculos pterigoideo medial e masseter (k"), ramo para a glândula salivar mandibular (c'), ramos para a glândula salivar parótida (c), ramo para o linfonodo mandibular (l) e ramos para o músculo cutâneo da face (e). Demais estruturas visualizadas: tendão de origem do músculo digástrico (t), artéria bucal (b), glândula salivar parótida (gp), glândula salivar mandibular (gm), ducto parotídeo (p), veia facial (f'), ramo bucal ventral do nervo facial (v), ramo do ramo bucal ventral do nervo facial (v'), músculo masseter parte superficial (mms) e músculo pterigoideo medial $(\mathrm{mpm})$. Barra de escala $=1 \mathrm{~cm}$.

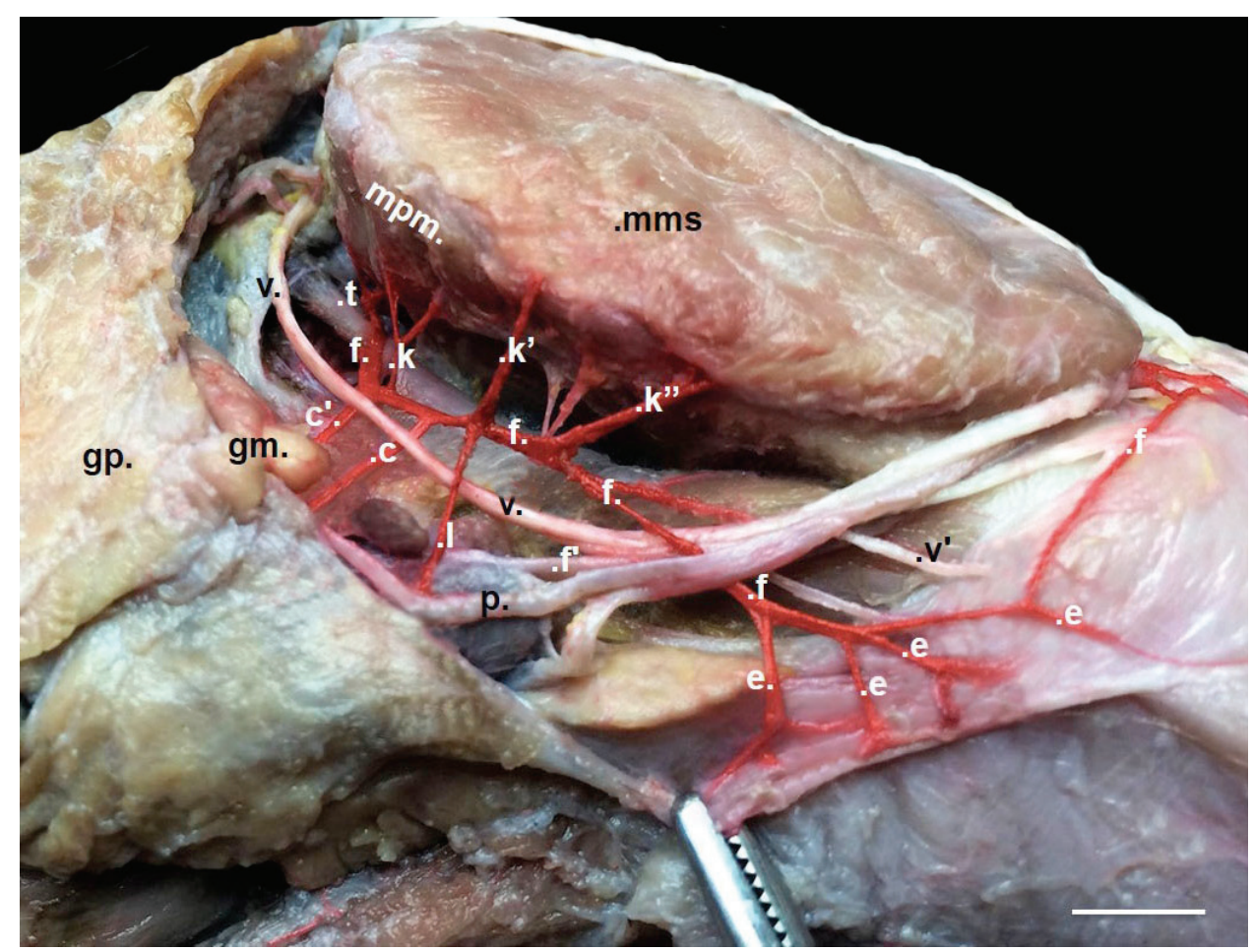


FIGURA 3: Distribuição da artéria facial de javali. Face lateral de hemicabeça direita de javali, com o músculo masseter partes superficial e média rebatidas. Notar a anastomose convergente (a) entre o ramo anastomótico da artéria bucal (b) e o ramo anastomótico da artéria facial (f). Demais artérias referenciadas: ramo da artéria bucal para o músculo masseter (b'), ramos da artéria bucal para o músculo cutâneo da face (b") e ramo da artéria bucal para o músculo bucinador parte molar (b"'). Músculos referenciados: músculo masseter parte profunda (mmp), músculo masseter parte média (mmd), músculo bucinador parte molar (bm) e músculo cutâneo da face (cf). Demais estruturas referenciadas: ângulo da hemimandíbula (g), glândula salivar mandibular (gm), glândula salivar parótida (gp), ramo bucal ventral do nervo facial (v), ducto parotídeo (p), veia facial (f') e ramo do ramo bucal ventral do nervo facial para o músculo depressor do lábio inferior (v'). Barra de escala $=1 \mathrm{~cm}$.

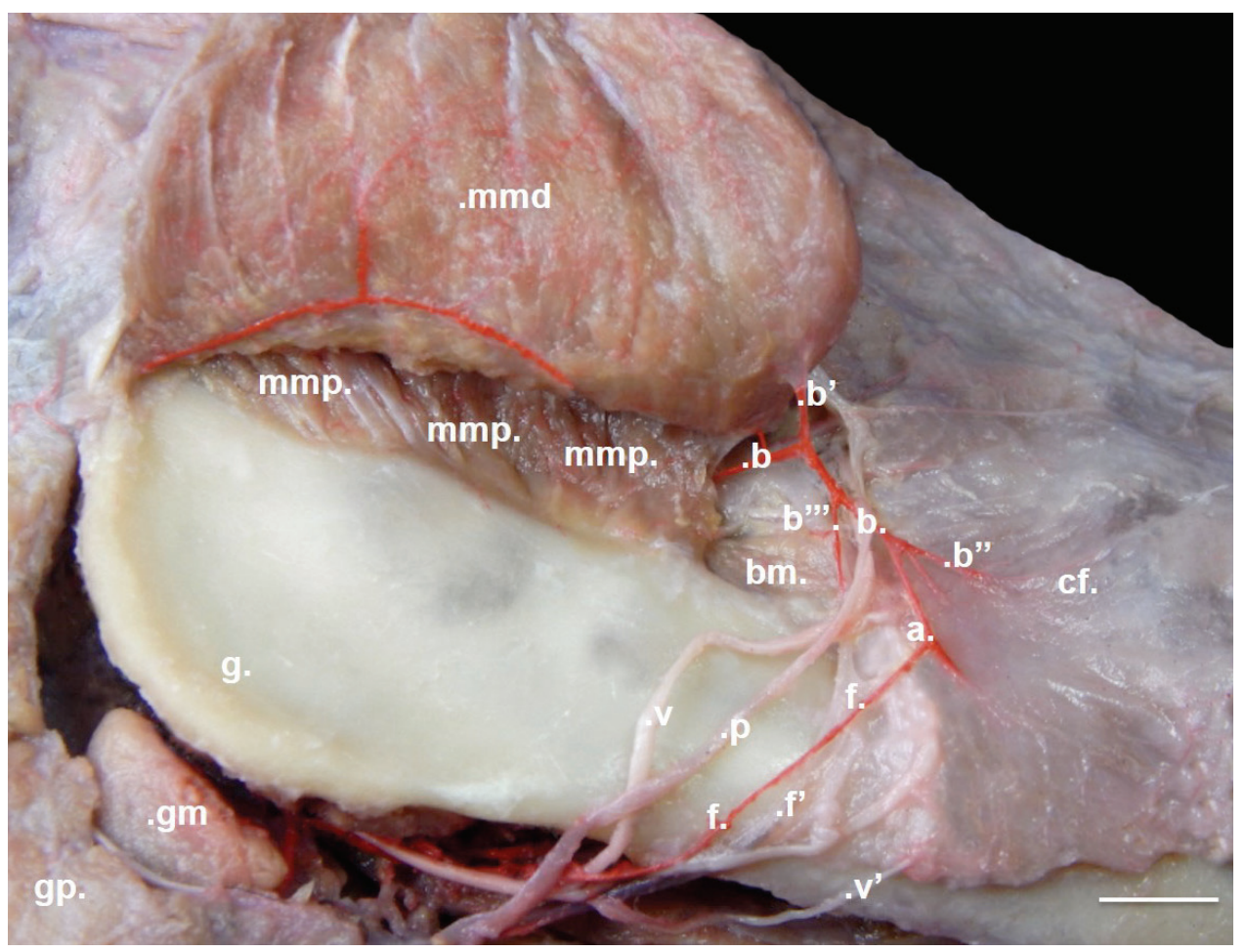


FIGURA 4: Distribuição da artéria facial de javali. Face lateral de hemicabeça esquerda de javali; dissecção da região temporal e parte da região intermandibular. Notar a anastomose convergente (a) do ramo milo-hioideo da artéria alveolar inferior (r) com a artéria facial (f), formando a artéria digástrica (d). Demais artérias referenciadas: artéria bucal (b), artéria alveolar inferior (i), artéria maxilar $(\mathrm{m})$, artéria temporal superficial $(\mathrm{t})$, tronco comum da artéria oftálmica externa com artéria meníngea rostral (o), artéria facial (f) e ramos da artéria facial para o linfonodo mandibular (1), glândula salivar parótida (c) e músculo cutâneo da face (e). Músculos em destaque: músculo pterigoideo medial $(\mathrm{pm})$ e músculo digástrico (md). Barra de escala $=1 \mathrm{~cm}$.

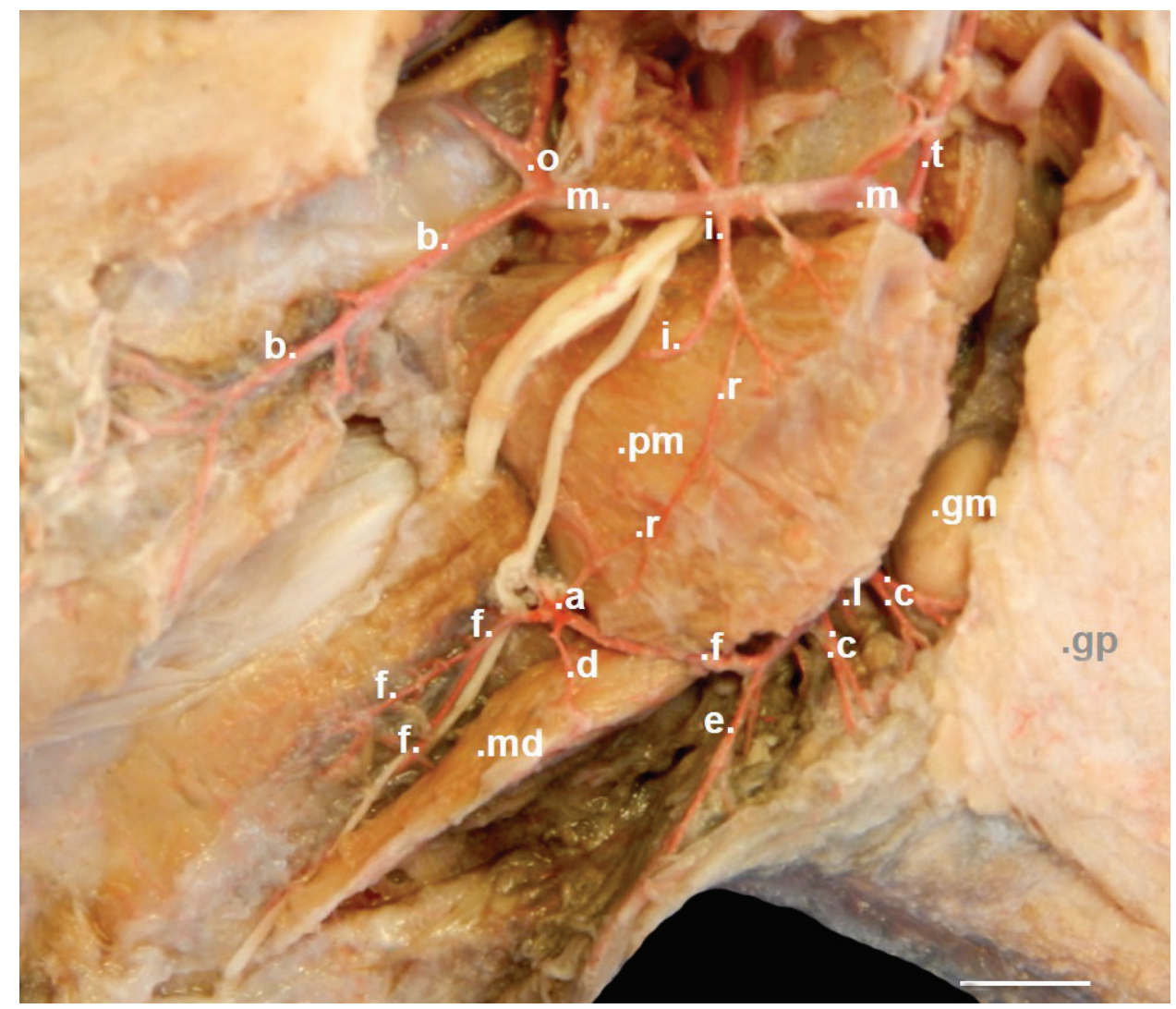

\section{Discussão}

Quanto às origens das artérias faciais direita e esquerda de javali, notou-se que, nas 12 hemicabeças dissecadas, foram provenientes das artérias carótidas externas direita e esquerda, conforme ressaltado por Nickel et al. (1981) em ruminantes domésticos, por Getty (1986) em suínos e carnívoros, por Ghoshal (1986) e Godinho et al. (1987) em bovinos, por Evans e de Lahunta (2001) em cão doméstico, por Dyce et al. (2004) em carnívoros e ruminantes domésticos, por Maia et al. (2014) em suínos natimortos da linhagem Sadia, assim como reportado por Silva-Júnior e Severino (2007) em $20 \%$ das 30 espécimes de bovinos natimortos da raça holandesa preta e branca, por Motheo et al. (2007) em $5 \%$ dos 20 fetos de bufalinos sem raça definida, bem como por Macêdo (2012) em 10\% dos fetos de bovinos azebuados (30 animais).

Entretanto, Bruni e Zimmerl (1977) e Ellenberger e Baum (1977) informaram que as artérias faciais nos suínos foram provenientes das artérias maxilares externas, ao passo que Getty (1986) em equinos e ruminantes, Ghoshal (1986) e Godinho et al. (1987) em bovinos ressaltaram que a artéria facial originou-se da artéria tronco linguofacial, que é um tronco comum tanto para artéria lingual quanto para artéria facial. Essa mesma origem também foi observada por Silva-Júnior e Severino (2007) em $80 \%$ dos 30 bovinos natimortos da raça holandesa preta e branca e por Motheo et al. (2007) em $70 \%$ dos 20 fetos de bufalinos sem raça definida, bem como por Macêdo (2012) em 90\% dos 30 fetos de bovinos azebuados. 
Ainda com relação à origem da artéria facial, é importante ressaltar que ela é inexistente nos caprinos e ovinos e, neste caso, o seu território de irrigação faz-se por meio da artéria transversa da face, conforme citação de Godinho et al. (1975) e de Getty (1986).

No javali, a origem da artéria facial ocorreu na margem lateroventral da artéria carótida externa, dorsalmente ao tendão de origem do músculo digástrico. A referida artéria se estendeu ventral e medialmente ao ramo e ângulo da mandíbula e, subsequentemente, inclinou-se rostralmente acompanhando medioventralmente o corpo da mandíbula. Quanto à distribuição, foram emitidos os seguintes ramos: ramo faríngeo, que se destacou da margem medial da artéria facial e se distribuiu para os músculos pterigoideo medial e estiloglosso, além da parede dorsolateral da faringe e palato mole; ramos musculares, tais como os ramos caudal, médio e rostral, que se destacaram dorsomedialmente para os músculos pterigoideo medial e masseter; ramos glandulares, emitidos para as glândulas salivares mandibular e parótida; ramos para os linfonodos mandibulares; ramos para o músculo cutâneo da face; ramos para o músculo digástrico; ramos para o músculo bucinador parte molar e ramos para o músculo milo-hioide.

Nickel et al. (1981) e Dyce et al. (2004) relataram que em suínos as artérias faciais são curtas, passam pela margem ventral da mandíbula e terminam no músculo masseter e na pele do espaço mandibular. Já Getty (1986) relata que nos suínos a referida artéria supre o músculo digástrico e o músculo pterigoideo medial, emitindo os ramos faríngeos, glandulares, musculares e que ainda pode emitir a artéria submentoniana. No atinente à distribuição da artéria facial, Maia et al. (2014), em suínos natimortos da linhagem Sadia, descrevem que ao longo da face são emitidos ramos glandulares que suprem as glândulas salivares mandibular e parótida, parte monostomática da glândula sublingual e lobo tímico cervical. Os ramos musculares irrigaram os músculos pterigoideo medial, masseter, face ventral do músculo digástrico e cutâneo da face; ramos faríngeos distribuíram-se para o palato mole, bula timpânica e músculo basi-hioideo e, por último, a artéria submentoniana se distribuiu para os músculos milohioideo e para a face dorsal do músculo digástrico.
Com base na distribuição da artéria facial do javali, e sabendo que esse animal é considerado como ancestral do porco doméstico (CROSBY, 1993), foram notadas poucas diferenças as quais se referem à presença de ramos para a bula timpânica, glândula salivar sublingual e para o lobo tímico cervical, o que de certa forma não chega a caracterizar as distribuições da artéria facial do javali como significativamente diferentes, uma vez que ramos da artéria facial para o lobo tímico cervical também seriam esperados neste suídeo, caso os espécimes avaliados fossem natimortos.

Ainda quanto às divergências, alguns autores supracitados, com raras exceções, são omissos quanto às distribuições em suínos, e, quando não, suas informações são pouco esclarecedoras. Neste aspecto, torna-se viável uma análise de natureza comparativa entre javalis e os demais animais domésticos.

O término da distribuição da artéria facial na condição de artéria submentoniana, como destacado por Nickel et al. (1981), Getty (1986), Dyce et al. (2004), Maia et al. (2014) para os suínos natimortos da linhagem Sadia, por Schwarze e Schröder (1972), Ghoshal (1986), Godinho et al. (1987) em bovinos, por Silva-Júnior e Severino (2007) em bovinos da raça holandesa preta e branca e por Macêdo (2012) em fetos de bovinos azebuados, não fora observado nos javalis, fato que não caracteriza esta situação como notória, uma vez que Getty (1986) cita que a artéria submentoniana nos suínos pode originar-se da artéria facial ou da artéria lingual. Já nos achados de Motheo et al. (2007) em fetos de bufalinos sem raça definida, a artéria submentoniana não foi encontrada no término da distribuição da artéria facial, tampouco da artéria lingual.

No tocante à distribuição da artéria facial nos ruminantes domésticos, esta se estendeu entre a glândula salivar mandibular e o ventre rostral do músculo digástrico, cruzou a margem ventral da mandíbula e se estendeu dorsalmente para ascender ao longo da margem rostral do músculo masseter e emitir os seguintes ramos colaterais: ramos glandulares, artéria submentual (SCHWARZE; SCHRÖDER, 1972; GHOSHAL, 1986; GODINHO et al., 1987), artéria labial inferior (SCHWARZE; SCHRÖDER, 1972; NICKEL et al., 1981; GHOSHAL, 1986; GODINHO et al., 1987), ramos 
superficial e profundo da artéria labial inferior, artéria labial superior, artéria angular da boca e artéria lateral rostral do nariz (SCHWARZE; SCHRÖDER, 1972; GHOSHAL, 1986; GODINHO et al., 1987).

Nos achados de Macêdo (2012) em fetos de bovinos azebuados, a artéria facial enviou diretamente vários ramos musculares para os músculos depressor do lábio inferior, elevador nasolabial, elevador do lábio superior, canino, malar, zigomático, bucinador, depressor do lábio superior, masseter e ramos glandulares que se distribuíram nas glândulas salivares mandibular e parótida. A artéria facial termina emitindo os ramos lateral nasal rostral, angular do olho e dorsal nasal em todos os casos (MACÊDO, 2012). Nos achados de Motheo et al. (2007), em fetos de bufalinos sem raça definida, a artéria facial emitiu as artérias labial mandibular superficial e profunda e a artéria labial maxilar.

Em equinos, as artérias faciais direita e esquerda penetram junto ao ducto parotídeo e, em seguida, ascendem ao longo da margem rostral do músculo masseter, dando origem aos ramos labiais inferior e superior, nasais laterais e dorsais e angulares dos olhos (SCHWARZE; SCHRÖDER, 1972). Dyce et al. (2004) descreveram que, em carnívoros, a artéria facial estende-se rostralmente à artéria lingual, medialmente ao músculo digástrico, seguindo rostrolateralmente entre os músculos digástrico e masseter para atingir a bochecha, lateralmente à mandíbula, onde supre os lábios e o nariz. Já Getty (1986) ressalta que a distribuição ocorre para o músculo digástrico, pterigoideo medial e masseter, bem como para a glândula salivar mandibular. De acordo com Evans e Christensen (1979), ela supre as glândulas salivares mandibulares e sublinguais, os músculos digástrico, pterigoideo medial e, ocasionalmente, o estiloglosso, podendo ainda se anastomosar com a artéria faríngea ascendente.

Já nos javalis analisados, nenhum ramo da artéria facial contribuiu para formação das artérias labiais superior e inferior, angular da boca, lateral rostral do nariz, angular do olho, dorsal nasal e tampouco foi evidenciada anastomose entre a artéria facial e a artéria faríngea ascendente.
Dignas de menção foram as duas anastomoses visualizadas ao longo do trajeto da artéria facial. Uma anastomose entre o ramo anastomótico da artéria bucal com o ramo anastomótico da artéria facial que, após convergirem-se, se distribuíram para o músculo bucinador parte molar. Essa anastomose diferencia-se da anastomose citada por Getty (1986) para suínos, pois, de acordo com o autor, a artéria facial anastomosa-se com um ramo anastomótico proveniente da artéria temporal profunda rostral.

Outra anastomose a ser destacada ocorre entre o ramo anastomótico da artéria facial e o ramo milo-hioideo da artéria alveolar inferior que, após convergirem-se, originam a artéria digástrica na face dorsolateral do músculo digástrico.

Podemos aventar que as diversas distribuições e as anastomoses ressaltam, respectivamente, a importância de alocação de sangue pelo vaso em questão na região intermandibular, bem como a necessidade de vias alternativas para passagem de sangue no javali, o que pode lhe conferir maior proteção para o desenvolvimento de suas atividades, visto que seu nicho ecológico e hábitos alimentares estão diretamente associados à prática de chafurdamento, ressaltada por Boughton e Boughton (2014), o que torna a região da cabeça completamente exposta durante o forrageamento e a defesa do animal.

Com base no exposto, as artérias faciais de javali originaram-se da artéria carótida externa em todos os espécimes e distribuíram-se em ramos faríngeo, glandulares, musculares e ramos para linfonodos mandibulares. Ramos anastomóticos da artéria facial com a artéria bucal e com o ramo milo-hioideo da artéria alveolar inferior foram identificados. Essa característica demonstra que a região de alocação da artéria facial nestes animais necessita de um expressivo contingente para irrigação, corroborando sua eficácia funcional, bem como com o modus viventis deste suídeo.

\section{Referências}

BAUBET, E.; BONENFANT, C.; BRANDT, S. Diet of the wild boar in the French Alps. Galemys, Malaga, v. 16 (Special Edition), p. 101-113, 2004. 
BOUGHTON, E. H.; BOUGHTON, R. K. Modification by an invasive ecosystem engineer shifts a wet prairie to a monotypic stand. Biological Invasions, Dordrecht, v. 16, n. 10, p. 2105-2114, 2014 .

BRUNI, A. C.; ZIMMERL, U. Anatomia degli animali domestici. Vol. 2. 2. ed. Milano: Casa Editrice Dr. Francesco Vallardi, 1977. $736 \mathrm{p}$.

CHOQUENOT, D.; MCILROY, J.; KORN, T. Managing vertebrate pests: feral pigs. Canberra: Australian Government Publishing Service, 1996. 163 p.

COURCHAMP, F.; CHAPUIS, J. L.; PASCAL, M. Mammal invaders on islands: impact, control and control impact. Biological Reviews, Cambridge, v. 78, p. 347-383, 2003.

CROSBY, A. W. Imperialismo ecológico. São Paulo: Companhia das Letras, 1993. 319 p.

DEBERDT, A. J.; SCHERER, S. B. O javali asselvajado: ocorrência e manejo da espécie no Brasil. Natureza \& Conservação, Curitiba, v. 5, n. 2, p. 31-44, 2007.

DYCE, K. M.; WENSING, C. J. G.; SACK, W. O. Tratado de anatomia veterinária. 2. ed. Rio de Janeiro: Elsevier, 2004. 813 p.

ELLENBERGER, W.; BAUM, H. Handbuch der vergleichenden anatomie der haustiere. Berlim: Sringern Verlag, 1977. 670 p.

EVANS, H. E.; CHRISTENSEN, G. C. Muscles. In: EVANS, H. E.; de LAHUNTA, A. (Ed.). MILLER's anatomy of the dog. 2. ed. Philadelphia: Saunders, 1979. p. 22-323.

EVANS, H. E.; de LAHUNTA, A. Guia para a dissecação do cão. 5. ed. Rio de Janeiro: Guanabara Koogan, 2001. 250 p.

FRANKENBERG, V. S. T. Levantamento e avaliação da Portaria 138/02 e Instrução Normativa 25/04, que regulamentaram o controle do javali (Sus scrofa) no Rio Grande do Sul no período compreendido entre 2003 e 2005. Produto PNUD, Projeto BRA/01/037, Brasília: Instituto Brasileiro do Meio Ambiente e dos Recursos Naturais Renováveis - Ibama. 2005. 250 p.

GENOV, P. Food composition of wild boar in northeastern and western Poland. Acta Theriologica, Warzana, v. 26, p. 185-205, 1981.

GETTY, R. Sisson/Grossman anatomia dos animais domésticos. Vol. 2. 5. ed. Rio de Janeiro: Guanabara Koogan, 1986. 2000 p.

GHOSHAL, N. G. Coração e artérias dos ruminantes. In: GETTY, R. (Ed.). Sisson/Grossman anatomia dos animais domésticos. Vol. 1. 5. ed. Rio de Janeiro: Guanabara Koogan, 1986. p. 900-959. GODINHO, H. P.; CARDOSO, F. M.; NASCIMENTO, J. F. Anatomia dos ruminantes domésticos. Belo Horizonte: Instituto de Ciências Biológicas da Universidade Federal de Minas Gerais, 1975. 415 p.
GODINHO, H. P.; CARDOSO, F. M.; NASCIMENTO, J. F. Anatomia dos animais domésticos. Belo Horizonte: Universidade Federal de Minas Gerais, 1987. 416 p.

INTERNATIONAL COMMITTEE ON VETERINARY GROSS ANATOMICAL NOMENCLATURE. Nomina anatomica veterinaria. 5. ed. Knoxville: World Association on Veterinary Anatomist, 2012. 160 p.

LONG, J. L. Introduced mammals of the world: their history distribution and influence. Collingwood: CSIRO, 2003. 612 p.

MACÊDO, E. C. Origem e ramificações das artérias faciais em fetos de bovinos azebuados. 2012. 24 f. Dissertação (Mestrado em Ciências Veterinárias) - Universidade Federal de Uberlândia, Uberlândia. 2012.

MAIA, R. A. C.; SEVERINO, R. S.; JÚNIOR, R. B. Origens, ramificações e distribuições das artérias faciais em suínos (Sus scrofa domesticus - Linnaeus, 1758) da linhagem Sadia. Veterinária Notícias, Uberlândia, v. 20, n. 1, p. 71-76, 2014.

MOTHEO, T. F.; MACHADO, M. R. F.; SOUZA, W. M.; OLIVEIRA, F. S. Origem e ramificação do tronco linguofacial em fetos de bufalinos sem raça definida (Bubalus bubalis bubalis). Acta Scientiae Veterinariae, Porto Alegre, v. 35, n. 2, p. 227-231, 2007.

NICKEL, R.; SCHUMMER, A.; SEIFERLE, E. The anatomy of the domestic animals. Vol. 3. Berlin: Verlag Paul Parey, 1981. 610 p.

OLIVER, W. L. R.; BRISBIN, JR, I. L. Introduced and feral pigs: problems, policy, and priorities. In: OLIVER, W. L. R. (Ed.). Pigs, peccaries and hippos: status survey and conservation action plan. Gland: International Union for the Conservation of Nature and Natural Resources, 1993. p. 179-191.

SCHWARZE, E.; SCHRÖDER, L. Compendio de anatomia veterinária. Vol. 3. Acribia: Zaragoza, Espanha, 1972. 315 p.

SILVA-JÚNIOR, N. F. S.; SEVERINO, R. S. Origens ramificações e distribuições das artérias faciais em bovinos da raça holandesa preta e branca. Horizonte Científico, Uberlândia, v. 1, n. 1, p. 1-21, 2007.

TIEPOLO, L. M., TOMAS, W. M. Ordem Artiodactyla. In: REIS, N. R.; PERACCHI, A. L.; PEDRO, W. A.; LIMA I. P. (Ed.) Mamíferos do Brasil. Londrina: Editora da Universidade Estadual de Londrina, 2006. p. 283-303.

VALÉRIO, L. A. J. Ocorrência e alimentação da linhagem javali (Sus scrofa, Mammalia, Artiodactyla) em estado silvestre no sudoeste do Rio Grande do Sul, Brasil. 1999. 56 f. Tese (Mestrado em Biologia Animal) - Universidade Federal do Rio Grande do Sul, Porto Alegre. 1999. 